\title{
Thinking Critically about Intellectual Liabilities: A Practice-Based Perspective
}

\author{
Marco Giuliani ${ }^{1}$ \\ ${ }^{1}$ Department of Management, Università Politecnica delle Marche, Ancona, Italy \\ Correspondence: Marco Giuliani, Department of Management, Università Politecnica delle Marche, Ancona, \\ Italy. E-mail: m.giuliani@univpm.it
}

Received: January 16, 2019

Accepted: February 12, 2019

Online Published: February 19, 2019

doi:10.5539/ijbm.v14n3p111

URL: https://doi.org/10.5539/ijbm.v14n3p111

\begin{abstract}
The aim of this study is to understand ILs for a practice-based perspective. This research will try to answer the following research questions: How do companies conceive ILs? How do they measure ILs? and how do they manage ILs? Alvesson and Deetz's (2000) critical management research framework was selected for the examination. The study is based on a field study that has involved large Italian companies.

The main findings are the following. First, there is a relevant gap between theory and practice as most of the ideas about ILs seem to have not entered into organizations. Second, the use of expressions like "intangible risk" appear to be more effective and understandable than "intellectual liabilities. as the word "intangibles" is more understandable than "intellectual capital". Third, companies tend to focus on human capital risks, customer risks, and IP risks as they are perceived as the most relevant ones. Fourth, ILs' measurements seem to be stand alone, ambiguous, simple and designed (or co-designed) by their direct users. Fifth, the management of ILs appear to be rather informal and fragmented.
\end{abstract}

Keywords: intellectual capital, intellectual liabilities, risk, intangibles, performance

\section{Introduction}

Within the IC discourse, the idea that Intellectual Capital (IC) has an important role in creating competitive advantages and a relevant influence on the organisational performance is dominant (Edvinsson and Malone, 1997; Stewart, 1997; Sveiby, 1997). This "grand theory" (Dumay, 2012) that argues that "the more IC, the better" appears to be too "optimistic" as IC can have both negative and positive effects, i.e. IC can both create and destroy value (Caddy, 2000; Garcia-Parra, et al., 2009; Majdalany and Manassian, 2012; Stam, 2009). Stemming from this, the concept of Intellectual Liabilities (ILs) has been introduced into the IC discourse to highlight the fact that IC can also have "negative value consequences" (Cuganesan, 2005, p. 360).

In literature, it is not possible to identify a unique definition of ILs even if they tend to be related with the ideas of wealth destruction and intangible risks or obligations (De Santis and Giuliani, 2013). In spite of the potential relevance of ILs within the IC discourse (Canibano and Garcia Ayuso, 2000; Garcia-Parra, et al., 2009; Stam, 2009), they are still "one of the most under-researched or, more realistically, avoided topics in the IC literature" (Dumay, 2013). This implies, among other things, that while the "asset side" of IC is in its "third stage" (Guthrie, et al., 2012), the research on ILs is still highly fragmented and the identification, measurement, and management of ILs are still considered to be problematic (De Santis and Giuliani, 2013). Due to this lack of studies, little is known about ILs in practice, i.e. how ILs are conceived, reported and managed by organisations. This is particularly relevant, as the issues related to ILs have gained momentum thanks to the fact several initiatives (e.g. Wici, IR, EU directive on non-financial reporting, etc.) have pushed forward the idea of reporting also the risks related to intangibles.

Moving from these considerations and in order to contribute to the debate about IC "in practice" (Dumay, 2013) and to answer the calls for investigations on ILs (Brunold and Durst, 2012; De Santis and Giuliani, 2013; Garcia-Parra, et al., 2009; Jääskeläinen, 2011; Mäenpää and Voutilainen, 2012), the aim of this paper is to understand ILs for a practice-based perspective. This research will try to answer the following research questions: How do companies conceive ILs? How do they measure ILs? And how do they manage ILs? To achieve this aim, a field study has been developed. Alvesson and Deetz's (2000) critical management research framework was 
selected for the examination. Here, the term "critical" is not used to find fault with current thinking, but rather to reflect on it.

The structure of this paper is as follows. The next section proposes a brief review of the literature regarding IC and ILs. Following that, the design of the study is described. The subsequent section reports the collected empirics then attempts to interpret the findings and to develop the theoretical arguments of the study. Finally, some valuable insights are extracted and discussed to draw some conclusions.

\section{Literature Review}

\subsection{On Intellectual Capital}

Over the last 20 years, IC has attracted the attention of scholars and practitioners. Three main stages of the IC discourse can be identified (Guthrie, et al., 2012). The first stage was characterised by the use of "grand theories" to create awareness about the strategic relevance of IC in creating and managing sustainable competitive advantage, i.e. it focused on "what IC is". The second stage, instead, centred the attention on the impact of IC on capital markets and value creation processes and on how IC should be managed to create and maintain a sustainable competitive advantage, i.e. on "what IC does". The third stage is centred on "IC in practice. i.e. on the use of IC measurements and the interplay between them and IC mobilisation and management. Indeed, it emerged that the effects, the benefits and the drawbacks of measuring and narrating IC have often been neither realised nor recognised in practice (Dumay, 2013; Guthrie, et al., 2012). In summary, it emerges the need to adopt a practice lens to understand what happens in vivo and develop "a critical examination of IC" (Guthrie, et al., 2012, p. 76). This study aims to contribute to this last stage.

As a multidimensional and heterogeneous phenomenon, IC can be approached from several perspectives (Gröjer, 2001; Mouritsen, et al., 2001) and this has led to a plethora of proposed concepts, methods, and tools but none of them, as yet, has gained a consensus (Chaminade and Roberts, 2003; Meritum, 2002; Mouritsen, et al., 2001; Stewart, 1997).

Concerning the IC concept, as said, it is not well understood and rarely defined clearly. By way of example, it is possible to find IC defined as the system composed of all of the firm's intangibles (Meritum, 2002), or as the sum of everything everybody in a company knows that gives it a competitive edge (Stewart, 1997), or as a combination of knowledge flows (Mouritsen, et al., 2001) or of connections between intangible resources (Chaminade and Roberts, 2003).

Even if there is a lack of a generally accepted definition of IC, regarding classification, there is the tendency to adopt the well-known tri-part model based on the identification of human capital, structural capital and relational capital (Guthrie, et al., 2012).

About the extant methods and tools, several IC accounting models and guidelines have attempted to understand and report IC. Sveiby (2010) and Andriessen (2004) find over 40 different methods and tools for approaching IC that are based on financial and non-financial measures and aim to support IC management and/or disclosure. These methods tend to adopt an analytical perspective, by focusing on single IC resources and activities, or a holistic one, i.e. they approach IC as a whole.

Even if IC has received great attention from scholars, according to Dumay (2013) IC is still more preached than practised. This idea finds support on some recent field studies that show that only a few companies have implemented the proposed IC concepts, methods and tools completely (Chiucchi, et al., 2018; Nielsen, et al., 2017). This lack of practice does not mean that companies do not measure IC: in fact, the mentioned research shows that IC measurements are often part of other managerial reports (e.g. sustainability reports, marketing reports, HR reports, strategic reports, etc.). In all, while IC measurements can be found in companies' reports, IC reports are rarely existing (and surviving) in practice.

Recently, the issues related to IC have moved to the Integrated Reporting (IR) domain, where intangibles continue to play a primary role but instead of being approached on a stand-alone basis here they are approached together with the other business "capitals" such as the financial, the social or the natural ones (de Villiers and Sharma, 2017). This means that IC measurements are combined with the ones related to the other capitals to offer a holistic perspective of the organisational value creation process.

In all, considering the extant publications on IC and the mentioned empirical studies, it seems that the IC discourse has reached a consolidated position in the academic studies and it has also managed, even if in different ways, to overcome the gap between theory and practice partly. 


\subsection{On Intellectual Liabilities}

While the positive effects of IC have been widely discussed, the risks and drawbacks related to the creation, development and disclosure of IC have often been overlooking even if they are relevant (Stam, 2009). Consequently, some argue that most of the studies about IC risk to be incomplete as they do not consider the possibility that organisations may incur obligations and risks in acquiring and maintaining IC (Garcia-Parra, et al., 2009; Giuliani and Marasca, 2011; Gowthorpe, 2009). In summary, there is the need to consider the existence adequately and the effects of ILs on the managerial and disclosure practices of an organisation.

These "negative value consequences" (Cuganesan, 2005, p. 360) have been variously described in the literature as "negative Intellectual Capital" (Brännström and Giuliani, 2009, p. 72). negative intangibles" (Ahonen, 2009; Gavious and Schwartz, 2008; Hall, 2001; Samudhram, et al., 2008). negative drivers of value creation" (Viedma Marti, 2003, p. 221). contradictory value drivers" (Abeysekera, 2006, p. 64) or "intellectual liabilities" (Caddy, 2000; Garcia-Parra, et al., 2009; Giuliani, 2013; Harvey and Lusch, 1999). More in-depth, scholars and practitioners have proposed two main concepts of ILs: the first considers ILs to be a depreciation of the value of IC (Abeysekera, 2003; Caddy, 2000) while the other assumes that ILs are risks or non-monetary obligations (Garcia-Parra, et al., 2009; Harvey and Lusch, 1999).

According to the former perspective, ILs can be considered: a) as an explanation of a negative difference between the market value of a company and its book value (Garcia-Parra, et al., 2009, p. 821); b) as a cause of an IC impairment (Caddy, 2000, p. 133); or c) as a form of "unaccounted items" that decrease the value of the firm (Abeysekera, 2003). With reference to the second perspective that considers ILs as risks, it aims to shed light on the fact that IC is volatile, difficult to manage and to protect and that its increase brings not only potential value creation but also additional risks that have to be understood and managed (Brunold and Durst, 2012; Kupi, et al., 2008). In other words, managers should be aware that increasing IC is convenient for the company until the potential benefits it can generate are bigger than the potential drawbacks.

Concerning the classification models, even if it is possible to identify different proposals, they tend to converge to the idea that there are internal (related to human resources and organisational processes) and external (related to the relationship between the firm and its stakeholders) ILs, consistently with IC. In this respect, some authors argue that ILs can be classified according to the typical IC tri-part model that distinguishes between human capital, structural capital and relational capital. In fact, in order to identify and classify the possible risks associated with each IC category, some authors have proposed a distinction between human capital risks, relational capital risks and structural capital risks (Brunold and Durst, 2012; Harvey and Lusch, 1999; Kupi, et al., 2008; Mäenpää and Voutilainen, 2012; Stam, 2009; Theeke and Mitchell, 2008).

Measuring ILs still appears to be an unsolved problem (De Santis and Giuliani, 2013). Also here, it is possible to identify holistic and analytical approaches. Concerning the former, some argue that ILs can be measured by referring to the difference between market value and book value or with similar approaches. About the latter, it is possible to identify a few models that can be used for reporting ILs (for a review, see De Santis and Giuliani, 2013) that tend to be designed as scorecard models where it is possible to identify indicators related to human, structural and relational capital. Sometimes, these indicators are presented next to the ones related to IC to create a framework able to present both the positive and the negative aspects of IC. Unfortunately, according to the extant literature, none of these models seems to have been applied in practice.

Measurements are technologies often used for managing. The issue of how to manage ILs seems to be the most overlooked in the literature. Kupi et al. (2008) argue that ILs tend to be overlooked by managers or to be managed following a rather informal approach that leads to the fragmentation of ILs among different managers (e.g. risk manager, HR manager, etc.) and to a lack of interaction between different responsibility areas in order to identify chains of events. They also suggest that the management of ILs should not focus only on minimising risks and their cost efficiently, but also on ensuring that the opportunities are utilised optimally (Kupi, et al., 2008)(Kupi, et al., 2008)(Kupi, et al., 2008). Mäenpää and Voutilainen (2012) suggest that some types of insurances provide potential solutions for the management of human capital risks as they "function as pre-emptive risk management tools and incentives for the desired behaviour, while others compensate policyholders in the occurrence of a pre-specified adverse event" (p. 62). Caddy (2001) and Caddy et al. (2001a; 2001b) propose a model useful for identifying and recovering orphan knowledge to avoid, or at least, reduce the risk of repeating past mistakes. To sum up, it remains unclear how ILs should be managed in practice or, more properly, controlled and minimised. The main lesson, however, that emerges from the extant studies is that ILs must be managed as well as IC is and that there is the managerial need to talk about them to understand and minimise the risk of losing value. 
In summary, ILs seem to be left out from the academic debate and very little is known about ILs in practice. Thus, there is the need to understand what companies do concerning this issue.

In comparison to the extant studies on ILs, this one adopts a practice-based perspective rather than a theoretical one (Caddy, 2000; De Santis and Giuliani, 2013). Also, it tries to offer an overview of the issues related to the identification, measurement and management of ILs rather than focusing on one single aspect (Kupi, et al., 2008). Finally, this study is not focused on the positive aspects of IC, as most of the IC literature does (Dumay, 2013), but on the negative ones.

\section{Design of the Study}

This study tries to answer the calls for investigations related to IC "in practice" (Dumay, 2013) and ILs "in practice" (De Santis and Giuliani, 2013; Giuliani, 2013, 2015). Thus, this research adopts the field study method to investigate how companies conceive and manage ILs. The field study method can be considered a research design that embraces a relatively small number of companies, as opposed to a wide-ranging survey or intensive case inquiries in two or three companies (Kaplan, 1986; Roslender and Hart, 2003; Scapens, 1990). Developing and administering a questionnaire was rejected as unlikely to produce the necessary level of detail or depth of insight required regarding managerial time perception. Intensive case research was also rejected because, despite its demonstrated capacity to provide rich accounts of practice and provocative insights, it may not capture the full range of such perceptions (Roslender and Hart, 2003). By analysing several organisations, it becomes possible to understand whether an emergent finding is simply idiosyncratic to a single case or consistently replicated in several cases (Eisenhardt, 1989; Eisenhardt and Graebner, 2007). Also, this method is considered suitable to explore "complex phenomena in a confined domain" (Lillis and Mundy, 2005, p. 131). In all, a field study method has been selected for this investigation because of its potential to provide a richer, more detailed understanding of a specific phenomenon.

This study is based on explorative case studies of six large Italian companies. The focus on Italian firms is because "Italy has become the new, hotbed of IC research, especially aimed at working side by side with managers inside organisations in developing IC practices" (Dumay, 2013, p. 6). The choice to investigate large companies is due to the following reasons: a) they tend to have more sophisticated accounting practices, that is, a management accounting system able to provide a broad spectrum of information relevant for planning, controlling, and decision-making all aimed at creating or enhancing value (Abdel-Kadera and Lutherb, 2008); b) large companies tend to have more IC (Brännström, et al., 2009; Guthrie and Petty, 2000). Limited resources meant that the study could not cover all the large Italian companies. Moreover, not all the contacted companies, identified adopting a purposeful sampling approach, were willing to take part in the project as it implied the communication of strategic and sensitive information. Therefore, the investigated companies (that will be indicated with a pseudonym) are the only ones that accepted to be part of the research project.

The main data-gathering technique was the semi-structured interview (Kreiner and Mouritsen, 2005; Qu and Dumay, 2011). This technique has been chosen because is well suited for the exploration of the perceptions and opinions of respondents regarding complex and sometimes sensitive issues. Also, it also allows the interviewer to probe for more information and elicit clarification of answers.

The research project was developed between 2016 and 2017. The first contact in the field was the investor relations manager of the companies who sent the researcher's request to the CEO or to the managing director who then approved the research project. He also identified the key participants in the study from within top management (CFOs, risk managers, internal auditors, etc.) to have participants with knowledge about organisational risks and an in-depth view of the company's value creation process. A list of questions was submitted to the interviewees beforehand. In the adopted semi-structured approach, open discussions were allowed to emerge. Therefore, when interesting and unexpected issues emerged during the interviews, it was possible to gather more information. The interviews lasted anywhere from one to two hours, depending on the complexity of the context and of the busy schedules of the respondents. Notes were taken during the meetings. After each one, the interview material and notes were examined to remove incomplete and ambiguous information. Contrasting perspectives were highlighted and, where necessary, confirmation of perspectives was requested from participants to ensure that it was the perspectives of those being studied which were being presented. Post-interview communication with the respondents helped the author to ensure the accuracy of the data.

The most valuable answers are reported and commented on in the next section. 


\section{Results' Overview}

The first aspect investigated was the idea of ILs. In particular, it was asked if and why they consider ILs as important.

ILs are very important. They can have a relevant negative impact on our organisation...

We strongly believe that intangibles are crucial to our success. Consistently, also the risks related to our intangibles are important...

Our CEO is very focused on this issue and in particular on the risks related to human capital and customer capital. So, he asked me [the CFO] to control these risks...

Our brands, customers, employees, etc. are important to us... we cannot risk to lose them. Thus, of course, we care about the risks related to our intangibles...

In all, it emerges that companies are aware of the existence of risks related to intangibles and IC even if none of the expression proposed by the extant studies was known or used by the interviewees. They were rather talking about risks related to intangibles.

After these preliminary questions, the focus of the interview moved to some more detailed aspects. In particular, firstly it was asked to describe the monitored ILs.

As said, we monitor the risks related to our human resources, to our IPs and our customer portfolio... They are the ones we consider as the most relevant as if something happens to them we will get into troubles...

We care a lot about the satisfaction of our customers... to have non-satisfied customers is a big risk...

We monitor the risks related to our human capital, to our brand, to our patents, to our customers...

Of course, there are a lot of risks that should be monitored, but we have to be selective and also consider what we can actually monitor...

As it is possible to notice, mostly all the interviewees have indicated three ILs as "the most relevant and monitored": human capital risks, customer capital risks and intellectual property (IP) risks. The companies have also highlighted that they were aware of the existence of other risks, but they were considered not as relevant or "too difficult" to monitor.

The limited number of identified ILs implied that none of the interviewed organisation has declared to adopt a specific classification model of the monitored ILs.

The second part of the interview regarded the measurement of ILs. In general, the interviewees declared that they tend to monitor these risks using specific procedures whose outcomes are specific (financial and non-financial) indicators and narratives.

Yes, we measure our human capital risks... we have an indicator regarding the turnover, one regarding the employees' satisfaction and one regarding incidents in the workplace...

We did not follow any guideline... we considered the data we have and the indicators we could calculate... So we have implemented indicators regarding employees' turnover, customer satisfaction, the trend of sales, etc.

We use financial and non-financial indicators. For example, the risks related to our brand are monitored considering the variation of its value; the risks related to our personnel are monitored by the HR manager with indicators regarding the turnover, career, benefits, and some other aspects;...

Concerning our customers, to monitor the risks, we use data about sales, satisfaction, credit rating, etc.

We do not have a report with all the risks... each manager monitor and control only "his risks" and report them to the $C E O$ and the board...

In general, ILs' indicators do not appear to be not integrated into a risk measurement system or in any accounting system, but they seem more to be part of departmental reports such as the human capital report, the marketing report, etc. Only some of the calculated indicators are included in the summary report examined by the top management.

All the companies considered as ILs' indicators the ones like the turnover of personnel, the hours of absence, number and relevance of working incidents, the trend of the sales, etc. It has to be noticed that these are indicators usually used for monitoring IC or its specific organisational dimensions (human resources, marketing, IPs, etc.) (Ordòñez de Pablos, 2002).

These indicators tend to be produced, in general, on a monthly base but some indicators are considered more 
"complicated" and, then, they are produced every six months or once a year.

An aspect that the two companies highlighted is related to the relationship between ILs and impairment test.

We use the data related to the intangibles' risks to understand if there is the need to impair some assets or to support the results of the impairment test or to supply some additional information in the management commentary...

Another question regarded who is the manager in charge of monitoring ILs. In general, there is not a specific role, but the monitoring of ILs is shared among different organisational departments: the human resource manager is in charge of controlling the risks related to human capital, the marketing manager is in charge of controlling the risks related to customer capital, etc. Even when there is a risk manager or an internal auditor, usually they are not in charge of monitoring the ILs directly in a systematic way, but they tend only to control that the manager in charge is monitoring them. Only in one case, the risk manager was indicated as the one who has to monitor all the risks, also the ones related to the strategic intangibles.

I [internal auditor] am not in charge of monitoring the risks related to patents or our personnel... If there is a high turnover of the personnel, it is not my business... I have to take care that there are no incidents in the workplace and that nobody commits frauds...

Of course, someone takes care of ILs... the human resource manager, the legal office, the marketing manager and the $C E O$...

Regarding the management of ILs, it is focused on the three types of risks identified: human resources risk, IP risks, and customer risks. From the analysis, it emerges that the idea of management of ILs is not related to specific codified systems, but more on informal processes developed during "managerial talks".

We discuss a lot about customer satisfaction... For us, it is a must to have satisfied customers...

During our meetings, we talk about our employees and our customers... if the indicators go in the "wrong" direction we talk a lot about the reasons of the variation and what we can do to improve; if they go in the "right" direction is everything quicker...

Human capital risks are always on the agenda of our human resource manager... he talks a lot about turnover, absenteeism, incidents, satisfaction, etc.

In all, the discussion seems to be devoted not to ILs as a system but more to single specific risks that are not managed systematically but more by single departments (HR, legal, marketing, etc.). Also, discussions tend to be more frequent or intense only when something "goes wrong".

\section{Discussion}

Alvesson and Deetz's (2000) critical framework underpins the following discussion of the collected evidence. These scholars call for three overlapping tasks to integrate critical social science into management research and practice - insight, critique, and transformative redefinition. "Insight helps develop understanding; critique examines the good and the bad; while transformative redefinition identifies new skills required to move forward and assists in the development of discourse about a particular phenomenon." (Dumay and Garanina, 2013, p. 13). This framework has been adopted in several studies relating to IC and management accounting (Dumay, 2009a, b, 2010; Dumay and Garanina, 2013; Giuliani and Skoog, in press) for its critical research perspective towards seeking new understanding and the possibilities of IC in practice.

\subsection{Insight}

Developing insight demands questioning knowledge that is taken for granted and examining the complex relationships between local forms of domination and their broader contexts. It relates to the interpretation of the data (Alvesson and Deetz, 2000), and, from an IC perspective, insight means attempting to understand the impact of practices on both human actors and their organisations to present new perspectives.

The collected evidence highlight different aspects of the identification, measurement and management of ILs from a practice-based perspective.

With reference to the concept of ILs, companies tend to conceive ILs as risks related to specific intangibles (Brunold and Durst, 2012; Kupi, et al., 2008). The other two concepts (depreciation and obligations) do not appear to be adopted in practice.

With reference to the identification of ILs, while in literature a plethora of ILs is identified (De Santis and Giuliani, 2013), in practice only three ILs tend to be considered: human capital risks, IP risks, and customer risks. These three items regard the more typical IC resources belonging to human capital, organizational capital and 
relational capital. It is curious that none of the companies considered as ILs the ones related to IT (risks of viruses, hackers' attacks, etc.) that, nowadays, can be particularly relevant. In all, it seems that there is not a complete awareness of the existence and relevance of ILs.

Regarding the classification model, the non-identification of a system of ILs but only of a few single items implies that there is no need to adopt a classification model (Gröjer, 2001). Nevertheless, the validity of the IC tri-part classification model seems to emerge as all the identified ILs can be classified according to the human capital, structural capital and relational capital "boxes".

ILs tend to be measured using "stand alone" non-financial indicators, i.e. not integrated into any specific system, as it has been recently found with reference to IC measurements (Chiucchi, et al., 2018). Some measurements, such as the customer satisfaction or the personnel turnover, can be included in the organisational performance measurement system or the risk measurement system but, more often, they are part of departmental reports. This situation contrasts with what scholars and practitioners suggest (De Santis and Giuliani, 2013), i.e. that companies should implement a specific accounting system related to IC and ILs. Furthermore, ILs' indicators tend to be rather simple (or sometimes even oversimplified) but able to make sense (Giuliani, 2016) to the managers. There are no cases where ILs' indicators are the result of sophisticated algorithms or complex procedures.

Moving from the production to the use of ILs' measurements, i.e. ILs' management, some scholars have analysed this issue with reference to IC highlighting that producers and main users can coincide or be different managers (Giuliani and Chiucchi, in press; Giuliani, et al., 2016). In the examined cases, producers and main users tend to coincide. Information regarding human capital tend to be produced and used mainly by the HR managers; information about customer satisfaction tend to be produced and used mainly by the marketing manager; etc. In all, also from a project actors' perspective, it seems that a holistic approach to ILs is missing: there is not a single sponsor or leader but several leaders that develop several little ILs' reporting projects, rarely coordinated.

\subsection{Critique}

The objective of critique "is to counteract the dominance of taken-for-granted goals, ideas, ideologies and discourses which put their imprints on management and organisation phenomena" (Alvesson \& Deetz, 2000, p. 18).

From the analysis of the insights referred to the concepts and classification models of ILs, a gap between theory and practice emerges. Some scholars have highlighted the fact that the term "IC" is often not adequately understood, as it tends to be used in order to describe specific intangibles such as intellectual property or human capital, etc., and, in rare cases, it is not known at all (Dumay, 2016; Giuliani, 2016; Giuliani and Chiucchi, in press). The term "ILs" was not known (never heard) by any of the interviewees: some that tried to guess the meaning referred to personnel or intellectual property. In all, the literature about ILs did not manage to have an impact on the real world, at least from a semantic perspective.

About the concept of ILs from a substantial perspective, it seems that the risks related to intangibles are not realised fully and, consequently, a rather limited picture of them is produced. This means that the issues related to ILs did not manage to enter into managerial or disclosure discourses and, consequently, managers risk being not completely aware of all the strategic risks related to IC and intangibles (Brunold and Durst, 2012; Kupi, et al., 2008). This situation seems to be hindered by the difficulties in identifying, understanding and controlling ILs and consequently, the focus tends to be on the more "traditional" ones that, sometimes, are also the most relevant.

With reference to the measurement of ILs, from the analysis, it emerges that none of the models proposed by scholars and practitioners to report ILs has been applied in the examined cases. ILs are not approached as a whole (as the extant models propose to do) but as single, stand-alone items. In other words, according to some recent studies, while IC measurements were first included in the IC report and then, after the demise of the IC reporting projects, become stand alone, ILs' measurements never had a phase of systemic reporting but it seems they were always part of broader managerial reports (e.g. marketing reports, HR reports, R\&D reports, etc.). This means that even if there is no ILs' report or "extended" IC report (with both assets and liabilities) in practice, some ILs are measured and controlled such as human capital risks, IP risks, and customer risks. This means that there is not a holistic view of the "negative side" of IC but a rather fragmented picture.

In addition, most of the measurements used to monitor ILs have been designed by the users and, according to the interviewees, they did not fall into the typical traps related to IC reporting, i.e. the search of the "perfect one" (Chiucchi, et al., 2018; Giuliani, et al., 2016), the "lock-in" (Chaminade and Roberts, 2003; Chiucchi and Dumay, 
2015) and the "wider still and wider" (Gowthorpe, 2009). More in depth, the search for the "perfect" measurements seems to be not identifiable with reference to ILs: companies tend to adopt proxies (such as HR turnover indexes for measuring the volatility of Human capital) without pushing for the design of "new" measurements. This is probably because ILs measurements are often not designed by accountants but by managers (risk managers, HR managers, etc.) that have no accounting background. For the same reason, i.e. ILs' measurements tend to be designed directly by their users that are often not belonging to the accounting department, there was no "lock-in" phenomenon as the measurements were implemented in order to be used and support managerial decisions. In other words, measurements were "pulled" by the users and not "pushed" forward by the accountants. Finally, the measurements have been designed with clear boundaries and for a specific purpose: none of them was supposed to have multiple purposes (e.g. internal and external reporting) as happened to the IC ones.

Regarding the management of ILs, the collected evidence appear to confirm the relationship between measuring and managing (Catasús, et al., 2007; Dumay and Rooney, 2011): the ILs that are measured are the ones that are managed thanks to the fact that managers talk about. All the other ILs tend to be overlooked. Also, the coincidence between producers and users of measurements, on the one hand, supports the usefulness of the measurement regarding capacity to lead to actions but, on the other hand, makes ILs an issue of a specific department and not of the whole organisation. For example, if the HR turnover is too high is the HR manager that has to address this problem. Furthermore, the collected data confirm the argument proposed by Kupi et al. (2008) who state that, although there are several procedures for managing IC in theory and practice, ILs tend to be managed following a rather informal and fragmented approach. In fact, in the examined cases, HR liabilities are managed by the HR manager, IP liabilities are managed by the risk manager or by the legal affair manager, the customer liabilities are managed by the marketing manager, etc. In summary, the management of ILs appears to be informal and fragmented as they are perceived as a departmental problem and not as an organizational one.

\subsection{Transformative Redefinition}

Transformative redefinition has implications for practice because it can lead to "managerially relevant knowledge and practical understandings that enable change and provide skills for new ways of operating" (Alvesson \& Deetz, 2000, p. 21). Rather than ending on a note of critique, its goal is to instigate new discussions that lead to non-repressive forms of organising. Research from this perspective explores alternative structures and arrangements to disrupt dominant discourses and established orders with an action component designed to foster personal, organisational, and social transformation (Alvesson and Deetz, 2000). In this vein, the critiques mentioned here are intended as opportunities to develop insights that can have theoretical and practical relevance.

With reference to the concept, ILs seem to suffer the accounting origin of IC and consequently the focus on the "asset side". The limited debate on the meaning of ILs has implied that there are quite different definitions of ILs (risks, obligations or depreciation) and none of them is known or understood in practice. Probably, as the expression "Intellectual Capital" seems to have not entered in most of the managers' vocabulary as they prefer to talk about "intangibles" (Chiucchi, et al., 2018), it would make more sense to abandon the expression "Intellectual liabilities" and push forward a label like "intangible risks" as it seems to be the one that is more understandable and used in practice. It is not a case that the International Integrated Reporting Framework (www.integratedreporting.org) uses this expression. The adoption of a specific, understandable jargon is crucial for grasping the attention of the managers and, consequently, for mobilising these items. In all, as there are scholars that suggest abandoning the expression "intellectual capital" and go back to the use of the word "intangibles" (Chiucchi, et al., 2018; Dumay, 2013; Giuliani and Chiucchi, in press), this paper suggest to abandon "Intellectual liabilities" and using "intangible risks".

As classifications are useful for making things understandable (Gröjer, 2001), the need for a model for visualising ILs will emerge when more than some few risks are identified. In this case, the implementation of one of the classification models proposed for reporting IC or intangibles (see, for example, the mentioned IC tri-part model or the model proposed by the IIRC based on 6 capitals) can be useful in order to have a picture both of the positive side and of the negative side of intangibles. Even if it will not be possible to represent directly the "intellectual equity. i.e. the difference between IC and ILs (Giuliani, 2013), the use of structured classification models able to integrate IC and ILs should be promoted. It supports the development of perceptions about the dimension of the "intellectual equity" through a process of sensemaking and logical comparison between IC and its risks.

With regard to the measurements, the indicators adopted by the interviewees appear to be characterised by 
ambiguity (Dumay and Rooney, 2011). In fact, the used indicators, such as "personnel turnover". customer satisfaction" or "trend of the sales. are frequently used to report both IC resources and ILs. For example, when the indicator regarding personnel turnover is low, it represents an IC indicator (stability of the firm's human capital) while when it is high, it represents a liability (risk of losing competences). In other words, an IC indicator becomes and IL indicator when it goes "in the wrong direction" as a manager said. This implies that, from a managerial perspective, ILs can represent the output of "non-actions" or of "wrong actions" and by narrating and numbering them the managers get aware of this, and thus they start doing "the right thing". Thus, it seems to confirm the argument proposed by De Santis and Giuliani (2013) that the ambiguity of measurements is particularly relevant in this context as it is the sense making process that defines what the indicator represents (a resource or a risk). The problem is this ambiguity is not compatible with most of the reporting models (see Meritum guidelines, IR framework, Wici framework etc.) that recommend showing risks, resources and performance in different sections. For example, with reference to the low index of turnover of the personnel, should it be reported as a (low) risk, as an attribute to the resource (human capital) or as a result of specific managerial activities (performance)?

The fact that ILs' measurements can be seen as simple or even simplistic can be considered a point of strength. Managers have implemented measurements that are easy to calculate and able to make sense to the user, and consequently, there were no cases of non-use like in the IC domain (Chiucchi, et al., 2018). This has also been highlighted in some recent studies about IC reporting that show that while IC reports have been abandoned, single, simple measurements meaningful for their users managed to survive (Chiucchi, et al., 2018; Nielsen, et al., 2017). In all, it seems that the theoretical discussions on IC and ILs' were too focused on the production of "perfect" numbers and not on their consumption: practice suggests that simple rules tend to be better (for managing) than complicated algorithms.

With regard to the management of ILs, it seems that there is the need to bring these risks into the managerial discussions. Most of the business models make lever on intangibles such as knowledge, IP, relationships, data, etc. (Beattie and Smith, 2013). The efforts that Wici and IIRC are doing for promoting their reporting frameworks that explicitly consider the risks related to intangibles should increase the awareness of ILs and improve the managerial processes. In other words, the hope is that the implementation of integrated reports, non-financial statements or other similar frameworks, on a voluntary or mandatory base, will bring some internal improvements. In particular, it would be important to raise the awareness that the value destruction process can take place (Giuliani, 2013), that ILs are "organizational issues" and not "departmental ones" (Kupi, et al., 2008) and that risk managers should be involved in the managerial discussions about intangibles as they rarely seem "on the scene" (Giuliani and Chiucchi, in press).

\section{Conclusions}

This paper aimed to understand ILs for a practice-based perspective. The research will try to answer the following research questions: How do companies conceive ILs? How do they measure ILs? And how do they manage ILs in their everyday life? In order to achieve this aim, a field study has been developed. Alvesson and Deetz's (2000) critical management research framework was selected for the examination.

The main results are the followings. First, there is a relevant gap between theory and practice as most of the ideas about ILs seem to have not entered into organisations. Second, the use of expressions like "intangible risk" appears to be more effective and understandable than "intellectual liabilities. as the word "intangibles" is more understandable than "intellectual capital". Third, companies tend to focus on human capital risks, customer risks, and IP risks as they are perceived as the most relevant ones. Third, ILs' measurements seem to be stand-alone, ambiguous, simple and designed (or co-designed) by their direct users. Even if these qualities can appear to be weaknesses, they are points of strength: all of the measurements are currently used and considered as satisfactory by their users. This seems to suggest that simple rules can be better (for managing) than complicated algorithms. Fourth, the management of ILs appear to be rather informal and fragmented: hopefully, the implementation of integrated reports, non-financial statements or other similar frameworks will lead to an improvement of the ILs' management processes.

In summary, up to date, ILs appears to be a topic that is under-investigated and overlooked in practice. The development of new international reporting initiatives, such as the Wici and the IR one, can offer the opportunity to raise the interest of scholars and practitioners on ILs (or intangible risks) and consequently bring the issues related to the identification, reporting and management of these risks to a new stage.

\section{Implications and Limitations}

This study contributes to the literature on IC in practice (Dumay, 2012; Guthrie, et al., 2012) incorporating the 
idea of ILs and the consideration that IC can create but also destroy value. It calls for a space within the IC and value creation discourse that also considers the negative effects. Additionally, this study emphasises the need to consider both IC and ILs within managerial, measurement and reporting practices: a better understanding of ILs is viewed as a fundamental contribution to the IC literature as it makes it possible to have a more complete and balanced picture of the concept of IC. In addition, it calls for rethinking the idea of ILs in the light of the latest reporting framework (e.g. IR framework, non-financial statement, Wici framework, etc.). In practical terms, a better understanding of how IC and ILs work can allow for better understanding of IC as a lever to create value and ILs as hidden negative values.

This study presents two main potential limitations. First, the results can be affected by the typical limitations of the design adopted for the study, that is, that a statistical generalisation is not possible and that the results may be subject to both interviewee and interviewer's bias and interpretation. Nevertheless, considering the exploratory nature of the study, one might be able to make an analytical generalization on some aspects. Second, it was not possible to interview all the companies of the existing Italian large companies. Even so, the investigated cases give an almost complete picture of what happens in reality.

\section{References}

Abdel-Kadera, M., \& Lutherb, R. (2008). The impact of firm characteristics on management accounting practices: A UK-based empirical analysis. British Accounting Review, 40(1), 2-27. http://dx.doi.org/10.1016/j.bar.2007.11.003

Abeysekera, I. (2003). Accounting for intellectual assets and intellectual liabilities. Journal of Human Resource Costing \& Accounting, 7(3), 7-14.

Abeysekera, I. (2006). The project of intellectual capital disclosure: Researching the research. Journal of Intellectual Capital, 7(1), 61-77.

Ahonen, G. (2009). On the mystery of odd human capital values. Journal of Human Resource Costing \& Accounting, 13(2), 118-124. https://doi.org/10.1108/14013380910968638

Alvesson, M., \& Deetz, S. (2000). Doing critical management research. Sage, London.

Andriessen, D. (2004). Making Sense of Intellectual Capital: Designing a Method for the Valuation of Intangibles. Elsevier Butterworth - Heinemann, Burlington, MA, USA.

Beattie, V., \& Smith, S. J. (2013). Value creation and business models: refocusing the intellectual capital debate. The British Accounting Review, 45(4), 243-254. https://doi.org/10.1016/j.bar.2013.06.001

Brännström, D., Catasús, B., Gröjer, J. E., \& Giuliani, M. (2009). Construction of Intellectual Capital. The case of purchase analysis. Journal of Human Resource Costing \& Accounting, 13(1), 61-76.

Brännström, D., \& Giuliani, M. (2009). Accounting for intellectual capital: A comparative analysis. VINE: The journal of information and knowledge management systems, 39(1), 68-79.

Brunold, J., \& Durst, S. (2012). Intellectual capital risks and job rotation. Journal of Intellectual Capital, 13(2), 178-195. https://doi.org/10.1108/14691931211225021

Caddy, I. (2000). Intellectual capital: recognizing both assets and liabilities. Journal of Intellectual Capital, 1(2), $129-146$.

Canibano, L., \& Garcia Ayuso, M. (2000). Accounting for intangibles: a literature review. Journal of Accounting Literature, 19, 102-130.

Catasús, B., Errson, S., Gröjer, J. E., \& Wallentin, F. Y. (2007). What gets measured gets... On indicating, mobilizing and acting. Accounting, Auditing \& Accountability Journal, 20(4), 505-521.

Chaminade, C., \& Roberts, H. (2003). What it means is what it does: A comparative analysis of implementing intellectual capital in Norway and Spain. European Accounting Review, 12(4), 733-751.

Chiucchi, M. S., \& Dumay, J. (2015). Unlocking intellectual capital. Journal of Intellectual Capital, 16(2), 305-330. https://doi.org/ 10.1108/JIC-01-2015-0004

Chiucchi, M. S., Giuliani, M., \& Marasca, S. (2018). Levers and barriers to the implementation of intellectual capital reports: A field study. In Guthrie, J., Dumay, J., Ricceri, F. \& Nielsen, C. (Eds.), The Routledge Companion to Intellectual Capital. New York: Routledge.

Cuganesan, S. (2005). Intellectual capital-in-action and value creation. A case study of knowledge transformation in an innovation process. Journal of Intellectual Capital, 6(3), 357-373. 
De Santis, F., \& Giuliani, M. (2013). A look on the other side: investigating intellectual liabilities. Journal of Intellectual Capital, 14(2), 212-226. https://doi.org/10.1108/14691931311323850

De Villiers, C., \& Sharma, U. (2017). A critical reflection on the future of financial, intellectual capital, sustainability and integrated reporting. Critical Perspectives on Accounting. http://dx.doi.org/10.1016/j.cpa.2017.05.003

Dumay, J. (2009a). Intellectual capital measurement: A critical approach. Journal of Intellectual Capital, 10(2), 190-210.

Dumay, J. (2009b). Reflective discourse about intellectual capital: Research and practice. Journal of Intellectual Capital, 10(4), 489-503. https://doi.org/10.1108/14691930910996607

Dumay, J. (2010). A critical reflective discourse of an interventionist research project. Qualitative Research in Accounting \& Management, 7(1), 46-70. https://doi.org/10.1108/11766091011034271

Dumay, J. (2012). Grand theories as barriers to using IC concepts. Journal of Intellectual Capital, 13(1), 4-15. https://doi.org/10.1108/14691931211196187

Dumay, J. (2013). The third stage of IC: towards a new IC future and beyond. Journal of Intellectual Capital, 14(1), 5-9. https://doi.org/10.1108/14691931311288986

Dumay, J. (2016). A critical reflection on the future of intellectual capital: from reporting to disclosure. Journal of Intellectual Capital, 17(1), 168-184. https://DOI.org/10.1108/JIC-08-2015-0072

Dumay, J., \& Garanina, T. (2013). Intellectual capital research: A critical examination of the third stage. Journal of Intellectual Capital, 14(1), =10-25. https://doi.org/10.1108/14691931311288995

Dumay, J., \& Rooney, J. (2011). "Measuring for managing?” An IC practice case study. Journal of Intellectual Capital, 12(3), pp. 344-355. https://doi.org/10.1108/14691931111154670

Edvinsson, L., \& Malone, M. S. (1997). Intellectual Capital. New York: Harper Business.

Eisenhardt, K. M. (1989). Building theories from case study research. Academy of Management Review, 14(4), $532-550$.

Eisenhardt, K. M., \& Graebner, M. E. (2007). Theory building from cases: opportunities and challenges. academy of Management Journal, 50(1), 25-32.

Garcia-Parra, M., Simo, P., Sallan, J. M., \& Mundet, J. (2009). Intangible liabilities: Beyond models of intellectual assets. Management Decision, 47(5), 819-830.

Gavious, I., \& Schwartz, D. (2008). The valuation implications of sales growth in start-up ventures. The Journal of Entrepreneurial Finance, 13(2), 1.

Giuliani, M. (2013). Not all sunshine and roses: Discovering intellectual liabilities "in action". Journal of Intellectual Capital, 14(1), 127-144. https://doi.org/10.1108/14691931311289057

Giuliani, M. (2015). Rome wasn't built in a day... Reflecting on time, intellectual capital and intellectual liabilities. Journal of Intellectual Capital, 16(1), 2-19. https://doi.org/10.1108/JIC-02-2014-0018

Giuliani, M. (2016). Sensemaking, sensegiving and sensebreaking: The case of intellectual capital measurements. Journal of Intellectual Capital, 17(2), 218-237. https://doi.org/10.1108/JIC-04-2015-0039

Giuliani, M., \& Chiucchi, M. S. (2019). Guess who's coming to dinner: the case of IC reporting in Italy. Journal of Management and Governance, 1-31. https://doi.org/10.1007/s10997-018-9432-x

Giuliani, M., Chiucchi, M. S., \& Marasca, S. (2016). A history of intellectual capital measurements: From production to consumption. Journal of Intellectual Capital, 17(3), 590-606. https://doi.org/10.1108/JIC-08-2015-0071

Giuliani, M., \& Marasca, S. (2011). Construction and valuation of intellectual capital: A case study. Journal of Intellectual Capital, 12(3), 377-391. https://doi.org/10.1108/14691931111154698

Giuliani, M., \& Skoog, M. (2019). Making sense of the temporal dimension of intellectual capital: A critical case study. Critical Perspectives on Accounting, 1-18.

Gowthorpe, C. (2009). Wider still and wider? A critical discussion of intellectual capital recognition, measurement and control in a boundary theoretical context. Critical Perspectives on Accounting, 20(7), 823-834.

Gröjer, J. E. (2001). Intangibles and accounting classifications: In search of a classification strategy. Accounting, 
Organizations and Society, 26(7), 695-713.

Guthrie, J., \& Petty, R. (2000). Intellectual capital: Australian annual reporting practices. Journal of Intellectual Capital, 1(3), 241-251.

Guthrie, J., Ricceri, F., \& Dumay, J. (2012). Reflections and projections: A decade of intellectual capital accounting research. The british accounting review, 44(2), 68-82. https://doi.org/10.1016/j.bar.2012.03.004

Hall, R. E. (2001). Struggling to understand the stock market. The American Economic Review, 91 No. 2, pp. $1-11$.

Harvey, M. G., \& Lusch, R. F. (1999). Balancing the intellectual capital books: Intangible liabilities. European Management Journal, 17(1), 85-92.

Jääskeläinen, A. (2011). How to measure and manage the risk of losing key employees?. International Journal of Learning and Intellectual Capital, 8(1), 63-75. https://doi.org/10.1504/IJLIC.2011.037359

Kaplan, R. S. (1986). The role for empirical research in management accounting. Accounting, Organizations and Society, 11(4), 429-452.

Kreiner, K., \& Mouritsen, J. (2005). The analytical interview: relevance beyond reflexivity. In Tengblad, S., Solli, R. and Czarniawska, B. (Eds.), The art of science. Kristianstad: Liber \& Copenhagen Business School Press.

Lillis, A. M., \& Mundy, J. (2005). Cross-Sectional Field Studies in Management Accounting Research-Closing the Gaps between Surveys and Case Studies. Journal of management accounting research, 17(1), 119-141.

Mäenpää, I., \& Voutilainen, R. (2012). Insurances for human capital risk management in SMEs. Vine, 42(1), 52-66. https://doi.org/10.1108/03055721211207761

Majdalany, G., \& Manassian, A. (2012). Voluntary disclosure of intellectual assets and intellectual liabilities: a literature review. In Surakka, J. E. (Eds.), Proceedings of the 4th European Conference on Intellectual Capital (ECIC). Academic Publishing International Limited, England.

Meritum. (2002). Proyecto Meritum. Guidelines for managing and reporting intangibles. Madrid.

Mouritsen, J., Larsen, H. T., \& Bukh, P. N. D. (2001). Intellectual capital and the 'capable firm': Narrating, visualising and numbering for managing knowledge. Accounting Organizations and Society, 26(7-8), 735-762.

Nielsen, C., Roslender, R., \& Schaper, S. (2017). Explaining the demise of the intellectual capital statement in Denmark. Accounting, Auditing \& Accountability Journal, 30(1), 38-64. https://doi.org/10.1108/AAAJ-04-2014-1671

Ordòñez de Pablos, P. (2002). Evidence of intellectual capital measurement from Asia, Europe and the Middle East. Journal of Intellectual Capital, 3(2), 287-302.

Qu, S. Q., \& Dumay, J. (2011). The qualitative research interview. Qualitative Research in Accounting \& Management, 8(3), 238-264. https://doi.org/10.1108/11766091111162070

Roslender, R., \& Hart, S. J. (2003). In search of strategic management accounting: theoretical and field study perspectives. Management Accounting Research, 14(3), 255-279.

Samudhram, A., Shanmugam, B., \& Lock Teng Low, K. (2008). Valuing human resources: an analytical framework. Journal of Intellectual Capital, 9(4), 655-667.

Scapens, R. W. (1990). Researching management accounting practice: The role of case study methods. The British Accounting Review, 22(3), 259-281.

Stam, C. D. (2009). Intellectual liabilities: lessons from The Decline and Fall of the Roman Empire. Vine, 39(1), 92-104.

Stewart, T. A. (1997). Intellectual Capital. New York, NY: Bantam Doubleday Dell Publishing Group.

Sveiby, K. E. (1997). The Intangible Assets Monitor. Journal of Human Resource Costing \& Accounting, 2(1), 73-97.

Theeke, H., \& Mitchell, J. B. (2008). Financial implications of accounting for human resources using a liability model. Journal of Human Resource Costing \& Accounting, 12(2), 124-137.

Viedma Marti, J. M. (2003). In search of an intellectual capital general theory. Electronic Journal on Knowledge Management, 1(2), 213-226. 


\section{Copyrights}

Copyright for this article is retained by the author(s), with first publication rights granted to the journal.

This is an open-access article distributed under the terms and conditions of the Creative Commons Attribution license (http://creativecommons.org/licenses/by/4.0/). 